ఠ

Open Access Full Text Article

REVIEW

\title{
Update and optimal use of a brinzolamide-timolol fixed combination in open-angle glaucoma and ocular hypertension
}

This article was published in the following Dove Press journal:

Clinical Ophthalmology

7 September 201 I

Number of times this article has been viewed

\author{
Misha F Syed \\ Emma KR Loucks \\ Department of Ophthalmology \\ and Visual Sciences, The University \\ of Texas Medical Branch, \\ Galveston, TX, USA
}

\begin{abstract}
Glaucoma encompasses a wide clinical spectrum of disease, with the common pathophysiology of progressive optic neuropathy leading to visual field loss. Elevated intraocular pressure (IOP) is a key risk factor in disease progression. Treatment is aimed at reduction of IOP to minimize continued optic nerve head damage. Pharmacologic treatment with various classes of IOP-lowering medications is generally employed before more aggressive surgical interventions. Monotherapy is generally accepted as initial therapy for glaucoma, but at least half of patients may require more than one IOP-lowering medication. One option is the fixed combination of brinzolamide $1 \%$ and timolol maleate $0.5 \%$, which is commercially available in some countries as Azarga ${ }^{\circledR}$ for treatment of glaucoma not adequately responsive to monotherapy. These agents may also be used in an unfixed fashion, but fixed combination therapy is generally more convenient for patients, which may result in improved compliance, a reduction of the "washout effect" from instilling multiple drops, and a potential reduction in the side effects related to multiple doses of preservatives.
\end{abstract}

Keywords: brinzolamide, timolol, glaucoma, fixed combination therapy, ocular hypertension

\section{Introduction}

Glaucoma is the second leading cause of blindness in the world. It is estimated that approximately 60.5 million people suffer from glaucoma. In the United States, it is estimated that almost three million people have open-angle glaucoma. By the year 2020 , it is predicted that 11.1 million people will be bilaterally blind from glaucoma worldwide. $^{1}$

Glaucoma is a characteristic optic neuropathy for which the only known modifiable risk factor is intraocular pressure (IOP). Other risk factors for progression of openangle glaucoma, cannot currently be altered. Therefore, therapeutic options focus on controlling the pressure inside the eye.

As with the management of any chronic, asymptomatic disease, challenges exist for both the patient and the physician. Treatment for glaucoma is generally chronic and may last decades. Even after surgical intervention, further IOP-lowering may be required. Patients most often do not notice small or moderate loss of peripheral vision as occurs early in the course of the disease, so as with other asymptomatic diseases, convincing patients that medications are crucial to preserving their vision can be difficult. Longterm use of eye drops reduces patient quality of life, and the more drops required, the greater the difficulty with and reported worsening of compliance. ${ }^{2}$ Balancing quality of life with the need for medications can be difficult, and any decrease in the number of drops may improve that balance.
Correspondence: Misha F Syed 700 University Boulevard, Galveston, TX 77555, USA

$\mathrm{Tel}+|\mathrm{I} 409747580|$

Fax +I 4097475402

Email mfsyed@utmb.edu 
Medications may be costly, troublesome to administer, and can cause side effects which range from irritating to dangerous. In choosing a drug regimen, the patient and physician must decide which treatment is most acceptable to both parties.

Major classes of medications include beta-blockers, alpha-adrenergic agonists, carbonic anhydrase inhibitors, and prostaglandin analogs. As more drug classes have become available, fixed combinations of these classes are being formulated. The fixed combination therapies currently available in the United States include dorzolamidetimolol (Cosopt ${ }^{\circledR}$, Merck Inc, Whitehouse Station, NJ) and brimonidine-timolol (Combigan ${ }^{\circledR}$, Allergan Inc, Irvine, CA). In Europe, fixed combinations of latanoprost-timolol $\left(\right.$ Xalacom $^{\circledR}$, Pharmacia Inc, New York, NY), travoprosttimolol (Duotrav ${ }^{\circledR}$, Alcon Inc, Fort Worth, TX), bimatoprosttimolol (Ganfort ${ }^{\circledR}$, Allergan Inc) and brinzolamide-timolol (Azarga $^{\circledR}$, Alcon Inc) are also available. Combination drugs may provide benefits of improved patient adherence and potential of reduced cost. This article will focus on the fixed combination of brinzolamide-timolol.

\section{Pharmacology}

There are no published data on the pharmacokinetics of the brinzolamide-timolol fixed-dose combination, but the pharmacokinetics of each individual drug are known. Brinzolamide is a highly specific and reversible carbonic anhydrase inhibitor. It targets carbonic anhydrase II, the predominant isoenzyme in the ciliary processes. Carbonic anhydrase II is also found in many other tissues of the body, including the corneal endothelium. The formation of bicarbonate ions is blocked by brinzolamide. This prevents sodium transport through the ciliary epithelium and results in decrease of aqueous humor formation. ${ }^{3}$

Timolol is a nonselective beta-adrenergic (beta- 1 and beta-2) receptor antagonist that blocks beta-adrenergic receptors in the ciliary body, which leads to a reduction of cyclic AMP-dependent aqueous humor formation. Beta antagonists were traditionally first-line treatment for IOP, but in recent years the prostaglandin analogs have generally replaced them as first-line therapy. ${ }^{4}$

Following ocular administration, systemic absorption of both medications does occur. The systemic effects of brinzolamide and timolol are discussed in the Safety section of this article.

With the issues surrounding patient compliance and tolerability of treatment, new and more efficacious modes of drug delivery are needed. Contact lenses have been developed with high loading and controllable sustained release of medication and are being tested for use in vitro. ${ }^{5}$ Hydrogels are insoluble, crosslinked polymer network structures composed of hydrophilic polymers, which have the ability to absorb water and retain their shape without dissolving. ${ }^{5}$ Hydrogel contact lenses imprinted with macromolecular memory could provide slow-release drug diffusion of glaucoma medications. Success with this type of treatment has not yet been demonstrated clinically, primarily due to the issue of matching release duration with the wear time of the contact lens and maintenance of suitable levels of drug concentration. ${ }^{5}$ Various in vivo rabbit studies done recently have demonstrated a prolonged therapeutic effect of ophthalmic medications with use of hydrogel contact lenses, resulting in a more stable prolonged drug level and longer retention time in tear fluid. ${ }^{6-8}$ The use of molecularly implanted therapeutic contact lenses remains theoretical but holds promise as a future treatment option.

\section{Efficacy studies}

Brinzolamide and timolol have documented efficacy in lowering IOP, as separate medications and in combination. Topical carbonic anhydrase inhibitors have been shown to reduce IOP by up to $24 \%$ when used as monotherapy and by an additional $15 \%$ when combined with timolol. ${ }^{9}$ Topical beta antagonists have been shown to lower IOP by 19\%-29\% when used as monotherapy. ${ }^{10}$ Twice or three times daily dosing of brinzolamide $1 \%$ produces an equally significant IOP reduction with no loss of efficacy for up to an 18-month period. ${ }^{11,12}$

Both brinzolamide $1 \%$ and dorzolamide $2 \%$ added to timolol $0.5 \%$ reduced IOP significantly compared with timolol alone, and both adjunctive treatments showed equivalent mean IOP-lowering ability as single agents. ${ }^{13}$ Various studies have evaluated the efficacy of fixed combination therapy. In a double-masked, randomized, parallel group, multicenter study with a six-month follow-up, a fixed combination of brinzolamide $1 \% /$ timolol $0.5 \%$ was compared with either brinzolamide $1 \%$ or timolol $0.5 \%$. The fixed combination of brinzolamide-timolol reduced IOP by approximately $8.0-8.7 \mathrm{mmHg}$ from baseline $(29.6 \%-33.5 \%)$. For timolol $0.5 \%$ twice daily and brinzolamide $1 \%$ twice daily, the IOP reduction from baseline ranged from 5.7 to $6.9 \mathrm{mmHg}$ $(22.8 \%-26.1 \%)$ and 5.1 to $5.6 \mathrm{mmHg}(18.9 \%-20.8 \%)$, respectively. The fixed combination of brinzolamide-timolol $0.5 \%$ was the most effective at lowering IOP at all visits and time points. These results showed that the fixed combination 
was superior in IOP-lowering efficacy compared with each of its individual components. ${ }^{14}$

A one-year, double-masked, prospective, randomized, multicenter, active-controlled, parallel-group clinical trial compared the fixed combinations of brinzolamide $1 \%$ / timolol $0.5 \%$ and dorzolamide $2 \% /$ timolol $0.5 \%$. Mean IOP reductions from baseline in the brinzolamide-timolol group varied from 7.2 to $9.1 \mathrm{mmHg}$ (reduced $28 \%-35 \%$ ) and in the dorzolamide-timolol group from 7.4 to $8.9 \mathrm{mmHg}$ (reduced by $29 \%-34 \%$ ). IOP was reduced to less than $18 \mathrm{mmHg}$ in up to $61 \%$ of eyes in the brinzolamide-timolol group and in up to $59 \%$ of eyes in the dorzolamide-timolol group. According to this study, the brinzolamide-timolol fixed combination demonstrated a significant ability to lower IOP, similar to the IOP-lowering ability of dorzolamide-timolol. ${ }^{15}$ This observation is logical, since in previous studies, the ability of the two carbonic anhydrase inhibitors to lower IOP when used alone is equivalent and the other ingredient in the combination, ie, timolol $0.5 \%$, is the same. ${ }^{16}$

Although it appears that no studies have evaluated the fixed combination of brinzolamide-timolol when added to a prostaglandin analog, three studies have examined brinzolamide added to a prostaglandin analog and a beta-blocker (two of which used the fixed combination of travoprost and timolol). These studies suggest that the addition of brinzolamide as a third medication to a prostaglandin analog and beta-blocker further reduces IOP significantly. ${ }^{17-19}$

Other factors besides IOP may be influential in the pathogenesis of glaucoma and therefore are important to consider when evaluating treatment options. Ocular perfusion is increasingly recognized as potentially playing a role in the disease. In a randomized, crossover, double-masked study of 15 patients who underwent evaluation of ocular blood flow, confocal scanning laser Doppler flowmetry suggested an increase in retinal blood flow with both brinzolamide and dorzolamide. Increased oxygen saturation in the retina was also measured by photographic retinal oximetry in the superior and inferior retinal veins with both medications. Color Doppler imaging found no significant change in retrobulbar blood supply with either medication..$^{20}$ In a literature review, meta-analysis of ocular blood flow and topical carbonic anhydrase inhibitors suggests that carbonic anhydrase inhibitors increase ocular blood flow velocities and reduce vascular resistance in the retinal circulation, specifically in the short posterior ciliary and central retinal arteries. More studies are needed to evaluate brinzolamide and its hemodynamic effects as well as the clinical significance of this finding. ${ }^{21}$

\section{Safety}

Although applied topically, brinzolamide and timolol are absorbed systemically. ${ }^{22}$ While not reported with topical use, ${ }^{23}$ some rare serious reactions can occur with oral carbonic anhydrase inhibitors including fulminant hepatic necrosis, Stevens-Johnson syndrome, and aplastic anemia. ${ }^{9}$ Oral carbonic anhydrase inhibitors have also caused significant systemic side effects due to the renal effects on electrolyte balance. ${ }^{9}$ Systemic adverse effects of the topical carbonic anhydrase inhibitors most commonly include a bitter/sour taste, headache, dermatitis, allergic reaction, dizziness, dry mouth, dyspnea, nausea, chest pain, kidney stones, and urticaria. $^{9}$ Ocular adverse effects include blurred vision, keratitis, burning/stinging/discomfort, allergic reaction, blepharitis, conjunctivitis, dryness, hyperemia, tearing, pruritus, photophobia, conjunctival edema, and discharge. ${ }^{9,23}$

Carbonic anhydrase II inhibition may affect the maintenance of stromal dehydration. In corneas predisposed to decompensation, this could cause further loss of corneal function and impaired vision. Care should be used in using carbonic anhydrase inhibitors in patients with compromised corneas, including those with low endothelial cell counts, corneal dystrophies, diabetes, or contact lens wearers. ${ }^{22}$

The beta-adrenergic component, timolol, may cause adverse reactions similar to systemic beta-blockers. ${ }^{22}$ These include bradycardia, arrhythmia, cardiac failure, heart block, syncope, and bronchospasm. Worsening of mental depression, impotence and/or loss of libido, and reduced exercise tolerance can also occur. ${ }^{9,24}$

Additionally, beta-adrenergic blocking agents may mask signs of acute hypoglycemia and hyperthyroidism and can worsen systemic hypotension. Other contraindications to beta-blocker use include a history of bronchial asthma, chronic obstructive pulmonary disease, or sinus bradycardia. ${ }^{22}$ Beta-adrenoreceptor antagonists may cause ocular side effects, such as foreign body sensation, redness, ocular burning/stinging, blurred vision, and decreased corneal sensation. ${ }^{9,24}$

The efficacy of topical timolol may be decreased by concomitant use of systemic beta-adrenoreceptor antagonists, and this may also increase systemic adverse effects. ${ }^{11}$ Punctal occlusion and avoiding blinking after placing the drop may lessen systemic absorption. Unless necessary, the brinzolamide-timolol fixed combination should not be used during pregnancy. Although it is not known whether brinzolamide appears in breast milk, timolol does. At therapeutic doses, no effects on breastfed infants are anticipated. ${ }^{22}$ 
Side effects noted with the brinzolamide-timolol fixed combination were similar to those of its individual components. In one study, the most common ocular side effect was blurred vision at $3.4 \%$ in the brinzolamide-timolol combination group compared with $2.9 \%$ in the brinzolamide group and $0.6 \%$ in the timolol group. Other ocular side effects in the fixed combination group included irritation/ burning $(2.9 \%)$, punctate keratitis $(1.7 \%)$, eye pain $(1.1 \%)$, eye pruritus $(1.1 \%)$, conjunctival hyperemia (1.1\%), foreign body sensation $(0.6 \%)$, corneal epithelium disorder $(0.6 \%)$, and ocular hyperemia $(0.6 \%)$. The most common nonocular adverse effect of the combination brinzolamide-timolol was dysgeusia (1.1\%), which had a lower occurrence than treatment with brinzolamide alone (4.6\%). Additionally, 1.1\% had a decrease in blood pressure, $0.6 \%$ experienced exacerbation of chronic obstructive pulmonary disease, and $0.6 \%$ had pharyngolaryngeal pain. ${ }^{14,25}$

In another study, the most common adverse ocular effects of the fixed combinations of brinzolamide-timolol and dorzolamide-timolol were blurred vision, eye pain, and irritation. Blurred vision occurred more commonly in the brinzolamide-timolol group than in the dorzolamidetimolol group (3.6\% versus $0.5 \%$ ), thought to be due to the suspension formulation. Ocular pain $(6.5 \%$ compared with $2.7 \%$ ) and irritation (10.6\% compared with $2.7 \%$ ) occurred more commonly in the dorzolamide-timolol group than in the brinzolamide-timolol group. Other ocular reactions included foreign body sensation and hyperemia. Dysgeusia was the most common nonocular side effect. Overall, the dorzolamidetimolol group had a significantly greater number of reported side effects ( $23 \%$ versus $14.1 \%),{ }^{15,16}$ demonstrating that the brinzolamide-timolol fixed combination may be better tolerated overall.

Because patient health as well as compliance with treatment can be directly affected by tolerability and/or adverse effects of medication, it is clearly important to be aware of the common reported effects of each medication, both as a single agent and in combination.

\section{Patient-focused perspectives}

Glaucoma patients face a unique challenge in the management of their disease. In contrast with many other ophthalmologic diseases, early glaucoma is often asymptomatic and causes little or no change in quality of life. In fact, it is often the treatment of glaucoma (most commonly in the form of eye drops) that negatively affects patient quality of life.

A major difficulty for many glaucoma patients is simply getting the drop(s) into their eyes. Most glaucoma patients are older and often suffer from debilitative joint disease which affects their manual dexterity. Glaucoma patients can also have varying degrees of visual disability, ranging from decreased contrast sensitivity to low vision from advanced loss of peripheral vision. These conditions can affect the ability of a patient to administer medication accurately and effectively from an eye drop bottle.

Financial issues may also adversely affect compliance. However, in one study, the cost of medications was not found to be a consistent factor in nonadherence to therapy among glaucoma patients. ${ }^{6}$ Difficulty in affording medication as a barrier to compliance may not be detected unless discussed directly with the patient. ${ }^{2}$ In general, patients with more advanced disease have higher treatment costs. ${ }^{26}$

Health literacy has been increasingly recognized as a potential barrier to adherence. Health literacy relates to the skills needed to read medicine labels and inserts, as well as other written health care information. It also includes the ability to understand information given by doctors, nurses, pharmacists, and other health care staff. ${ }^{27}$ It has been shown that those with poor health literacy are much more likely to miss appointments, to miss eye drops, and to refill their medications fewer times. ${ }^{27,28}$

Complicated dosing schedules may also contribute to nonadherence. Several studies have found that taking multiple types of medications and/or taking an increased number of doses per day could result in decreased compliance. ${ }^{2}$

The use of a fixed combination medication could potentially improve compliance with medical therapy and thereby improve outcomes. Fixed combination drugs have several advantages. They may be more efficacious in lowering IOP when combined into one formulation. This also decreases long-term preservative exposure and severity of side effects. Washout effect from administering one drop after another is also eliminated. Fixed combination medications simplify dosing by just having one bottle to use (and to refill) and they also decrease the frequency of applications. All of these factors may have a positive impact on patient compliance and IOP control..$^{23,25}$

Compliance with topical medications is likely linked to comfort issues. Multiple studies have demonstrated brinzolamide to be more comfortable and preferred by patients to dorzolamide, the other major topical carbonic anhydrase inhibitor available for treatment of glaucoma. ${ }^{13,17,29-31}$ In a prospective, double-masked, randomized, active-controlled, crossover, multicenter study, patients were asked to evaluate ocular discomfort associated with the brinzolamide-timolol fixed combination versus the dorzolamide-timolol fixed 
combination. Over $80 \%$ in the study expressed a preference in medication, and of those, approximately $80 \%$ chose brinzolamide-timolol, which had significantly lower ocular discomfort scores compared with dorzolamide-timolol. Brinzolamide-timolol caused more transient blurred vision and dorzolamide-timolol had more reported ocular irritation and pain. However, it seems patients preferred transient blurring of vision over ocular pain or discomfort. ${ }^{16,25,32}$

In a prospective, double-masked, parallel-group, randomized clinical trial, the brinzolamide-timolol group reported significantly less ocular discomfort than the dorzolamidetimolol group after one week. More than three times as many patients in the brinzolamide-timolol group reported no ocular discomfort after one week of therapy (49\% versus $15 \%$ ). Both groups had a statistically significant mean increase in ocular discomfort scores from baseline; however, the increase was less pronounced in the brinzolamide-timolol group. ${ }^{16,25,33}$

The more physiologic $\mathrm{pH}$ of brinzolamide may be the reason for greater ocular comfort, ${ }^{32,33}$ and this may be true of the fixed combination medications as well. Brinzolamidetimolol has a more physiologic $\mathrm{pH}$ of $7.2^{22}$ as compared with 5.6, the more acidic $\mathrm{pH}$ of dorzolamide-timolol. ${ }^{34}$ Additionally, $\mathrm{pH}$ also affects solubility. At physiologic $\mathrm{pH}$ and room temperature, brinzolamide has a limited solubility, so a suspension form is used to maximize delivery. ${ }^{22,25}$ In contrast, dorzolamide and dorzolamide-timolol were formulated as a solution with a buffering system using sodium citrate. This buffering system could be another explanation for difference in comfort. It has also been suggested that the intrinsic molecular differences between the fixed combinations may account for the reported variation in comfort, ${ }^{33,34}$ although both contain timolol and a carbonic anhydrase inhibitor, so the dissimilarity in comfort is not likely to be molecular. ${ }^{32}$

Therapy with an adjunctive third glaucoma medication, specifically with a prostaglandin analog and a betablocker (either a fixed combination or monotherapy) with brinzolamide added does not appear to elicit any additional serious side effects. ${ }^{17-19}$

\section{Costs}

The direct and indirect costs of being afflicted with glaucoma are difficult to estimate. Studies in the literature have focused on the direct costs of glaucoma, namely the cost of medications. Indirect costs including lost income due to visual disability have been less explored. ${ }^{2,26}$ Costs associated with screening for glaucoma need to be considered as newer screening modalities are developed, including possible genetic testing for certain types of glaucoma.
Studies looking at the "cost-of-illness" from glaucoma found that costs for patients with primary open-angle glaucoma were higher than for those with ocular hypertension. ${ }^{26}$ Patients with mild and/or controlled primary open-angle glaucoma had the lowest costs. ${ }^{26}$ One European study found that medications accounted for about half of total direct costs in primary open-angle glaucoma patients, and a French study reported that combination therapies were almost twice as expensive as monotherapy. ${ }^{26}$ It is clear that the costs of glaucoma are lower when the disease is diagnosed and treated early, which suggests that accurate diagnosis and early intervention could decrease costs associated with the disease. ${ }^{26}$

\section{Conclusion}

The fixed combination of brinzolamide and timolol has been shown to be more efficacious than each of its components individually and equivalent in efficacy as a fixed combination when dosed against the simultaneous administration of its two components. It also has a similar safety profile in comparison with existing glaucoma medications. The added utility of providing two medications in one formula may improve patient compliance with the medication. Clinicians will need to judge if a fixed combination medication such as brinzolamide-timolol is the best choice for their patients, because individuals may have varying degrees of tolerability and response to the treatment. If an adverse effect is noted, the combination drug may need to be discontinued and each component individually evaluated. Glaucoma remains a disease with extremely diverse manifestations and treatment must be tailored to each patient in order to attain the best clinical outcome and prevent significant visual loss.

\section{Acknowledgment}

This work was supported by an unrestricted grant from Research to Prevent Blindness.

\section{Disclosure}

The authors report no conflicts of interest in this work.

\section{References}

1. Quigley HA, Broman AT. The number of people with glaucoma worldwide in 2010 and 2020. Br J Ophthalmol. 2006;90(3):262-267.

2. Tsai JC. A comprehensive perspective on patient adherence to topical glaucoma therapy. Ophthalmology. 2009;116(11 Suppl):S30-S36.

3. Rhee DJ, Rapuano CJ, Papaliodis GN, Fraunfelder FW, editors. Physicians 'Desk Reference for Ophthalmic Medicines. 39th ed. Montvale, NJ: PDR Network, LLC; 2010.

4. Allingham RR, Damji KF, Freedman S, Moroi SE, Shafranov G, Shields MB, editors. Shields'Textbook of Glaucoma. 5th ed. Philadelphia, PA: Lippincott Williams and Wilkins; 2005. 
5. White CJ, Byrne ME. Molecularly imprinted therapeutic contact lenses. Expert Opin Drug Deliv. 2010;7(6):765-780.

6. Singh V, Bushetti SS, Appala R, Shareef A, Imam SS, Singh M. Stimuli-sensitive hydrogels: A novel ophthalmic drug delivery system. Indian J Ophthalmol. 2010;58:477-481.

7. Hui-Hui A, Qiu-Hua L, Zhi-Jun Y, Wei-San P, Shu-Fang N. Novel ophthalmic timolol maleate liposomal-hydrogel and its improved local glaucomatous therapeutic effect in vivo. Drug Delivery. Epub 2011, May 1. Available from informahealthcare.com. Accessed August 15, 2011.

8. Xu J, Xinsong L, Fuqian S. In vitro and in vivo evaluation of ketotifen fumarate-loaded silicone hydrogel contact lenses for ocular drug delivery. Drug Deliv. 2011;18(2):150-158.

9. Tsai JC, Forbes M. Medical Management of Glaucoma. 3rd ed. Caddo, OK: Professional Communications Inc; 2009.

10. Shaarawy T, Sherwood MB, Hitchings RA, Crowston JG. Glaucoma: Medical Diagnosis and Therapy, Volume 1. Beijing, China: Elsevier Limited; 2009.

11. March WF, Ochsner KI. The long-term safety and efficacy of brinzolamide $1.0 \%$ (Azopt) in patients with primary open-angle glaucoma or ocular hypertension. The Brinzolamide Long-Term Therapy Study Group. Am J Ophthalmol. 2000;129(2):136-143.

12. Silver LH. Clinical efficacy and safety of brinzolamide (Azopt), a new topical carbonic anhydrase inhibitor for primary open-angle glaucoma and ocular hypertension. Brinzolamide Primary Therapy Study Group. Am J Ophthalmol. 1998;126(3):400-408.

13. Michaud JE, Friren B. Comparison of topical brinzolamide $1 \%$ and dorzolamide $2 \%$ eye drops given twice daily in addition to timolol $0.5 \%$ in patients with primary open-angle glaucoma or ocular hypertension. Am J Ophthalmol. 2001;132(2):235-243.

14. Kaback M, Scoper SV, Arzeno G, et al. Intraocular pressure-lowering efficacy of brinzolamide $1 \% /$ timolol $0.5 \%$ fixed combination compared with brinzolamide $1 \%$ and timolol $0.5 \%$. Ophthalmology. 2008;115(10): 1728-1734.

15. Manni G, Denis $P$, Chew $P$, et al. The safety and efficacy of brinzolamide $1 \% /$ timolol $0.5 \%$ fixed combination versus dorzolamide $2 \% /$ timolol $0.5 \%$ in patients with open-angle glaucoma or ocular hypertension. J Glaucoma. 2009;18(4):293-300.

16. Hollo G, Bozkurt B, Irkec M. Brinzolamide/timolol fixed combination: A new ocular suspension for the treatment of open-angle glaucoma and ocular hypertension. Expert Opin Pharmacother. 2009;10(12): 2015-2024.

17. Tsukamoto H, Noma H, Matsuyama S, Ikeda H, Mishima HK. The efficacy and safety of topical brinzolamide and dorzolamide when added to the combination therapy of latanoprost and a beta-blocker in patients with glaucoma. J Ocul Pharmacol Ther. 2005;21(2):170-173.

18. Goldberg I, Crowston JG, Jasek MC, Stewart JA, Stewart WC. Intraocular pressure-lowering efficacy of brinzolamide when added to travoprost/timolol fixed combination as adjunctive therapy. J Glaucoma. November 2, 2010. [Epub ahead of print].

19. Hollo G, Kothy P. Intraocular pressure reduction with travoprost/ timolol fixed combination, with and without adjunctive brinzolamide, in glaucoma. Curr Med Res Opin. 2008;24(6):1755-1761.
20. Siesky B, Harris A, Cantor LB, et al. A comparative study of the effects of brinzolamide and dorzolamide on retinal oxygen saturation and ocular microcirculation in patients with primary open-angle glaucoma. $\mathrm{Br} J$ Ophthalmol. 2008;92(4):500-504.

21. Siesky B, Harris A, Brizendine E, et al. Literature review and metaanalysis of topical carbonic anhydrase inhibitors and ocular blood flow. Surv Ophthalmol. 2009;54(1):33-46.

22. European Medicines Agency. European Public Assessment Report (EPAR): Azarga. Available from: http://www.ema.europa.eu/docs/ en_GB/document_library/EPAR_-_Summary_for_the_public/ human/000960/WC500029824.pdf. Accessed January 19, 2011.

23. Kanner E, Tsai JC. Glaucoma medications: Use and safety in the elderly population. Drugs Aging. 2006;23(4):321-332.

24. Bartlett JD, editor. Ophthalmic Drug Facts. St Louis, MO: Facts and Comparisons; 2003.

25. Hollo G. Brinzolamide/timolol fixed combination for open-angle glaucoma and ocular hypertension. Exp Rev Ophthalmol. 2009;4(2): 129-133.

26. Schmier JK, Halpern MT, Jones ML. The economic implications of glaucoma: A literature review. Pharmacoeconomics. 2007;25(4): 287-308.

27. Juzych MS, Randhawa S, Shukairy A, Kaushal P, Gupta A, Shalauta N. Functional health literacy in patients with glaucoma in urban settings. Arch Ophthalmol. 2008;126(5):718-724.

28. Muir KW, Santiago-Turla C, Stinnett SS, et al. Health literacy and adherence to glaucoma therapy. Am J Ophthalmol. 2006;142(2): 223-226.

29. Barnebey H, Kwok SY. Patients' acceptance of a switch from dorzolamide to brinzolamide for the treatment of glaucoma in a clinical practice setting. Clin Ther. 2000;22(10):1204-1212.

30. Stewart WC, Day DG, Stewart JA, Holmes KT, Jenkins JN. Short-term ocular tolerability of dorzolamide $2 \%$ and brinzolamide $1 \%$ vs placebo in primary open-angle glaucoma and ocular hypertension subjects. Eye (Lond). 2004;18(9):905-910.

31. Silver LH. Ocular comfort of brinzolamide $1.0 \%$ ophthalmic suspension compared with dorzolamide $2.0 \%$ ophthalmic solution: Results from two multicenter comfort studies. Brinzolamide Comfort Study Group. Surv Ophthalmol. 2000;44 Suppl 2:S141-S145.

32. Mundorf TK, Rauchman SH, Williams RD, Notivol R. A patient preference comparison of Azarga (brinzolamide/timolol fixed combination) vs Cosopt (dorzolamide/timolol fixed combination) in patients with open-angle glaucoma or ocular hypertension. Clin Ophthalmol. 2008;2(3):623-8.

33. Vold SD, Evans RM, Stewart RH, Walters T, Mallick S. A one-week comfort study of BID-dosed brinzolamide $1 \% /$ timolol $0.5 \%$ ophthalmic suspension fixed combination compared to BID-dosed dorzolamide $2 \% /$ timolol $0.5 \%$ ophthalmic solution in patients with open-angle glaucoma or ocular hypertension. J Ocul Pharmacol Ther. 2008;24(6): 601-605.

34. Merck Sharp and Dohme Corporation. Available from: http://www. merck.com/product/usa/pi_circulars/c/cosopt/cosopt_pi.pdf. Accessed February 7, 2011.
Clinical Ophthalmology

\section{Publish your work in this journal}

Clinical Ophthalmology is an international, peer-reviewed journal covering all subspecialties within ophthalmology. Key topics include: Optometry; Visual science; Pharmacology and drug therapy in eye diseases; Basic Sciences; Primary and Secondary eye care; Patient Safety and Quality of Care Improvements. This journal is indexed on Submit your manuscript here: http://www.dovepress.com/clinical-ophthalmology-journal

\section{Dovepress}

PubMed Central and CAS, and is the official journal of The Society of Clinical Ophthalmology (SCO). The manuscript management system is completely online and includes a very quick and fair peer-review system, which is all easy to use. Visit http://www.dovepress.com/ testimonials.php to read real quotes from published authors. 